\section{MMR Vaccine and Covid-19: A Myth or a Low Risk-High Reward Preventive Measure?}

Published data highlights that immunity conferred by vaccination against Measles-Rubella (MR) vaccine persists for at least 20 years, and is generally thought to be lifelong for most individuals [1]. Emerging data speculates the role of live attenuated vaccines and the concept of 'trained innate immunity' offered by Bacillus Calmette Guerin (BCG) and MMR vaccine as an immune-prophylaxis against SARS-CoV 2 [1]. The molecular theory is based on overlapping of vaccine epitopes and amino acid residues between the Spike (S) glycoprotein of the SARS-CoV-2 virus with the Fusion (F1) glycoprotein of measles virus and the envelope (E1) glycoprotein of the rubella virus that possibly results in children presenting with a milder version of COVID-19 disease in contrast to adults [2]. As a result of these hypotheses, there has been an increase in adults opting to vaccinate themselves with the MMR vaccine.

We feel that this data may be more applicable to the Western population, particularly in the United States, and may not be applicable in India [3,4]. Firstly, the Serum Institute of India Ltd manufactures the MMR vaccine used in India. This contains the Edmonston-Zagreb measles virus strain, which provides long-term sero-persistence of antibodies against measles in a majority of vaccinees as compared to other brands found across Western countries [3]. Secondly, a study of 192 college students in India found that the sero-prevalence of antibodies (IgG) to the three components of MMR vaccine was $91 \%, 97 \%$, and $88 \%$, respectively, even though $96 \%$ of the study population did not recollect their vaccination history [5]. Both of these studies suggest that antibodies to measles might well persist into adulthood and the need for an MMR vaccine to boost immunity may not be essential.

Okada, et al. [6] compared the analysis of host responses related to immunosuppression following natural measles infection and vaccination with a live attenuated measles vaccine and concluded that in contrast to wild-type measles virus (natural infection), live measles vaccines did not provoke the host cytokine response that leads to apoptotic cytolysis of uninfected lymphocytes, lymphopenia and immunosuppression, and thereby induced weaker immune responses to the virus. Published data from the United Kingdom (UK) revealed that macro domains of SARS-CoV-2 and rubella virus share $29 \%$ amino acid sequence identity, suggesting they have a similar protein fold. A cellular homolog of the methyltransferase from SARS coronavirus can be found in E.coli with
$65 \%$ sequence identity and viral homologs are detected in numerous coronaviruses, concluding that the observed homology is similar to an anamnestic reaction to SARS-CoV-2 by mounting $\operatorname{IgG} / \operatorname{IgM}$ response of rubella antigen and that MMR will not prevent COVID-19 infection but could potentially reduce poor outcome, which may be more of a speculation without appropriate randomized control trials [7].

In summary, while there are many theoretical hypotheses to prove the concept of trained immunity offered by BCG and MMR vaccines, well-designed controlled studies are needed, before considering MMR vaccination as a low risk-high reward tool to prevent COVID-19.

Acknowledgement: Dr S Balasubramanian, Medical Director, Kanchi Kamkoti CHILDS Trust Hosiptial, Chennai for suggesting this write up and providing data.

Published online: July 24, 2020; PII: S097475591600216

SANJAY DESHPANDE ${ }^{{ }^{*}}$ AND SARATH BALAJI
${ }^{2}$ Pediatrics and Pediatric Infectious Diseases,
Manipal Hospitals, Bengaluru, Karnataka; and
${ }^{2}$ Department of Pulmonology,
Institute of Child Health,Egmore,
Chennai, Tamil Nadu; India.
${ }^{*}$ deshpande.sanjay29@gmail.com

\section{REFERENCES}

1. Shanker V. Measles immunization: Worth considering containment Strategy for SARS-CoV-2 global outbreak. Indian Pediatr. 2020; 57:380.

2. Fidel PL, Noverr MC. Could an unrelated live attenuated vaccine serve as a preventive measure to dampen septic inflammation associated with COVID-19 Infection? mBio. 2020;11:e00907-20.

3. Sidiq KR, Sabir DK, Ali SM, Kodzius R. Does early childhood vaccination protect against COVID-19? Front Mol Biosci. 2020;7:120.

4. Raut S, Kulkarni P, Phadke M, Jadhav S, Kapre S, Dhere R, et al. Persistence of antibodies induced by measlesmumps-rubella vaccine in children in India. Clin Vacc Immunol. 2007;14:1370-1.

5. Gohil D, Kothari S, Chaudhari A, Gunale B, Kulkarni P, Deshmukh R, et al. Seroprevalence of measles, mumps, and rubella antibodies in college students in Mumbai, India. Viral Immunol. 2016;29:159-63.

6. Okada H, Sato T, Katayama A, Higuchi K, Shichijo K, Tsuchiya $\mathrm{T}$, et al. Comparative analysis of host responses related to immunosuppression between measles patients and vaccine recipients with live attenuated measles vaccines. Archives of Virology. 2001;146:859-74.

7. Caprari S, Metzler S, Lengauer T, Kalinina OV. Sequence and structure analysis of distantly-related viruses reveals extensive gene transfer between viruses and hosts and among viruses. Viruses. 2015;7:5388-409. 